\section{SOI: $1.1 /$ TAS
International Scientific Journal $10.15863 / \mathrm{T} A S$ Theoretical \& Applied Science}

p-ISSN: 2308-4944 (print) e-ISSN: 2409-0085 (online)

Year: $2016 \quad$ Issue: $10 \quad$ Volume: 42

Published: 30.10.2016 http://T-Science.org

SECTION 8. Architecture and construction
Vita Zakharchuk

Assistant

Odessa State Academy of Civil Engineering and Architecture

Odessa, Ukraine tzvvxxx@gmail.com

Serhiy Kolykhanin

Assistant professor

Odessa State Academy of Civil Engineering and Architecture

Odessa, Ukraine ocean2_buh@ukr.net

Natalia Shyshkalova

Assistant professor

Odessa State Academy of Civil Engineering and Architecture

Odessa, Ukraine shishkalova7@mail.ru

\title{
DETERMINATION OF THE PLANNED POSITION
}

\begin{abstract}
The global navigation satellite system (GNSS) is the modern satellite technique for definition of the coordinates of geodetic networks' points. This led to the transition to the geocentric coordinate systems and the coordinate reference systems with the beginning at the center of the Earth. One of the first systems was the World geodetic system 1984 (WGS84) developed by the US DoD. It is used to solve the international economic problems.

With the increasing accuracy of the GPS technique, the International Terrestrial Reference System (ITRS) functionates since 1990, with the practical implementation of the International Terrestrial Reference Frame (ITRF). Although the scope of WGS84 is wider, but ITRF provides higher location accuracy.

As a result of observations on the Ukrainian permanent GNSS network the parameters were simulated and the state geodetic coordinate system USK-200 was introduced. It was obtained from the coordinate system ITRS/ ITRF 2000 and fixed for the epoch J2000.0. However, Ukrainian surveyors still use a conventional coordinate system SC-63, abolished 30 years ago.

Key words: reference ellipsoid, artificial satellites, geodetic networks, satellite observing systems, coordinate systems, permanent station.

Language: Russian

Citation: Zakharchuk V, Kolykhanin S, Shyshkalova N (2016) DETERMINATION OF THE PLANNED POSITION. ISJ Theoretical \& Applied Science, 10 (42): 52-54.

Soi: http://s-o-i.org/1.1/TAS-10-42-12 Doi: crossef http://dx.doi.org/10.15863/TAS.2016.10.42.12
\end{abstract}

\section{ОПРЕДЕЛЕНИЕ ПЛАНОВОГО ПОЛОЖЕНИЯ}

Аннотация: Современным способом определения координат пунктов геодезических сетей является спутниковый - с помощзью Глобальных навигационных спутниковых систем (ГНСС). Это обусловило переход к геочентрическим системам координат и референцным с началом в ичентре Земли. Одной из первых таких систем стала, разработанная МO США Мировая геодезическая система WGS84, которая используется для решения народнохозяйственных задач международного уровня.

C повышением точности метода GPS с 1990 года действует Международная референцная система ITRS с практической реализацией через отсчетную основу ITRF. Хотя схема применения WGS84 более широкая, но ITRF обеспечивает более высокую точность определения местоположения.

В результате наблюдений на Украинской перманентной сети ГНСС были смоделированы параметры и введена государственная геодезическая система координат УСК-200, полученная от координатной системы ITRS/ ITRF 2000 и зафиксированная на эпоху 2000 года.

Вместе с тем, украинскими землеустроителями до сих пор еще используется условная система координат - СК-63, отмененная 30 лет назад.

Ключевые слова: референи-эллипсоид, искусственный спутник, геодезические сети, спутниковые системы наблюдений, системы координат, перманентная станция 


\section{Введение}

Плановое положение точек местности определяется координатами. В СССР и до 2004 года на Украине действовала система координат СК-42, которая была введена постановлением Совета Министров СССР №760 от 07.04.1946г. Она базировалась на референц-эллипсоиде выдающегося ученого-геодезиста Ф.Н.Красовского. Размеры этого референцэлипсоида определены в 1940 году в центральном научно-исследовательном институте геодезии, аэросъемки и картографии и были вычислены по имеющимся на то время астрономо-геодезическим и гравиметрическим наблюдениями на пунктах геодезических сетей огромной территории Советского Союза.

\section{Основные исследования}

Новая эра в уточнении параметров общеземного эллипсоида открылась из наблюдений за искусственными спутниками Земли (ИСЗ). Передвигаясь в изменчивом поле тяготения, спутники чутко реагируют на все вариации этого поля, уточняя фигуру геоида и тем самым обнаруживая "несовершенство" национальных референц-эллипсоидов, на которых базируются принятые в этих странах системы координат. Важно, что эти уточнения происходят без использования огромных объемов геодезических и гравиметрических измерений. [1]

Таким образом, современнейшим способом определения координат пунктов геодезических сетей является спутниковый - с помощью Глобальных навигационных спутниковых систем (ГНСС).

Поэтому появилась насущная проблема разработки теоретических основ для перехода к геоцентрическим - общеземным и таким референцным системам координат, в которых начало координат размещено в центре Земли, ось $\mathrm{Z}$ направлена на северный полюс, оси $\mathrm{X}, \mathrm{Y}$ лежат в плоскости экватора, причем ось $\mathrm{X}$ проходит через точку пересечения Гринвичского (нулевого) меридиана с экватором, а ось $\mathrm{Y}$ дополняет принятую систему координат до правой, т.е. под углом $90^{\circ}$ на восток.[2]

И для решения народнохозяйственных задач межгосударственного уровня в Украине принята Мировая геодезическая система пространственных координат WGS84 (World Geodetik System), разработанная Министерством обороны США в 1991 году. Начало системы находится в центре масс Земли, ось $\mathrm{Z}$ совпадает с осью вращения отсчетного эллипсоида и направлена на Северный условный земной полюс (СЗП), положение которого зафиксировано Международным бюро времени (МБВ) на эпоху 1984,0. Ось X находится на пересечении плоскости начального (Гринвичского) меридиана с плоскостью экватора. Начальный меридиан МБВ определен на эпоху 1984,0. Ось Ү - в плоскости экватора и дополняет систему до нулевой, т.е. под углом $90^{\circ}$ на восток. Большая полуось эллипсоида WGS84 a=6378137,00 м, сжатие $\boldsymbol{\alpha}=$ $1: 298,257223563[1,9]$

Повышалась точность метода GPS, увеличивалось количество наблюдательных станций и это требовало повышения точности координатной системы. Набор координат 17 станций 2001 года обозначен WGS84 (G1150). G обозначает, что реализация системы полностью основывается на GPS наблюдениях, а 1150 - номер недели относительно эпохи 1984,0. Стандартное отношение по каждой координате станции составляет $1 \mathrm{~cm}$.

Практическая реализация системы через наборы точек (наземных пунктов) называется отсчетной основой (reference frame). С 1990 года начинает действовать Международная земная референцная основа International Terretial Referece Frame (ITRS) - это набор геодезических пунктов с точно определенными координатами в Международной земной референцной системе. Начало системы ITRS находится в центре масс всей Земли, включая океаны и атмосферу, и ориентировка осей задана по данным МБВ на эпоху 1984,0. Практически отсчетная основа ITRF 2000 идентична отсчетной основе WGS84. Благодаря измерениям на более 200 перманентных станциях по всему миру ITRF учитывает дрейф материков. Хотя ITRF позволяет получить более высокую точность определения местоположения геодезических пунктов, чем WGS84, но сфере применения WGS84 значительно шире (навигация, ГИС, геология, геофизика и т.д.). $[9,10]$

В настоящее время отсчетная основа ITRF является наиболее точной реализацией общеземных систем.

Когда выяснилось, что точность определенных и уравновешенных координат пунктов Государственной геодезической сети не отвечает точности определения этих координат спутниковым методом и геодезические измерения существенно искажаются при привязке к пунктам Государственной геодезической сети, то была создана Украинская перманентная сеть Глобальных навигационных спутниковых систем (ГНСС) и с 2003 года начались работы по модернизации Государственной геодезической сети. Было выполнено моделирование параметров новой геодезической референцной системы координат Украины. И постановлением Кабинета Министров Украины №1259 от 22.09.2004 года "Некоторые вопросы применения геодезической системы координат" для использования всеми субъектами топографо-геодезической и картографической деятельности $[3,4,5,6,8]$ c 
01.01.2007 года вводится Государственная геодезическая референцная система координат УСК 2000, полученная от координатной системы ITRS/ITRF 2000 и зафиксированная на эпоху 2005 года.

УСК 2000 заменила ранее действовавшую в Украине систему координат СК 42, построенную на референц-эллипсоиде Ф.Н.Красовского, центр которого практически (с разницей первых сотен метров) совпадает с центром ITRF.

В основе УСК 2000:

- референц-эллипсоид Красовского в качестве поверхности отсчета с параметрами большая полуось $6378245 \mathrm{~m}$, сжатие 1:298,3;

- масштаб равен масштабу системы ITRS/ ITRF 2000;

-ориентировка осей координат параллельна осям координат системы ITRS/ ITRF 2000;

- центр системы координат обеспечивает минимальное отклонение поверхности референцэллипсоида от реальной поверхности Земли на регион Украины.

Положение пунктов Государственной геодезической сети определяется в таких системах координат:

пространственных прямоугольных координатах $\mathrm{X}, \mathrm{Y}, \mathrm{Z}$ (ось Z совпадает с осью вращения эллипсоида, ось $\mathrm{X}$ лежит в плоскости нулевого меридиана, а ось Ү дополняет систему до правой; началом системы координат является геометрический центр эллипсоида);

геодезических (эллипсоидальных) координатах: с широтой - В, долготой - L и высотой - Н;

- в плоских прямоугольных координатах X и Y, которые вычисляются в проекции Гаусса Крюгера.

\section{Заключение}

Государственная геодезическая система задает на всей территории страны Государственную референцную систему координат и распространяет с необходимой точностью и плотностью пунктов общеземную систему координат.

Следует отметить как крайне негативное явление то, что землеустроители до сих пор по незнанию или неумению используют условную систему координат 1963 года СК-63, отмененную постановлением ЦК КПСС Совета Министров СССР от 25 марта 1987 года №373-85. [7]

\section{References:}

1. Antonovich KM (2006) Ispolzovanie sputnikovyih radionavigatsionnyih sistem $\mathrm{V}$ geodezii (tom 2). M.: Kartgeotsentr, Novosibirsk: Nauka, 2006. - 360 p.

2. Voitenko SP (2012) Inzhenerna heodeziia / S.P.Voitenko. K.: Znannia, 2012. - 575p.

3. (2012) Zakon Ukrainy "Pro vnesennia zmin shchodo derehuliatsii hospodarskoi diialnosti $\mathrm{z}$ provedennia robit $\mathrm{z}$ zemleustroiu ta zemleotsinochnykh robit” №5394-VI vid 02.10.2012.

4. (1999) Instruktsiia $\mathrm{Z}$ topohrafichnoho znimannia u masshtabakh 1:5000, 1:2000, 1:1000, 1:500.-K.,1999. - 155p.

5. Postanova KM (2014) Ukrainy "Pro optymizatsiiu systemy tsentralnykh orhaniv" № 442 vid 10.09.2014.

6. Postanova KM (2009) Ukrainy "Pro zatverdzhennia osnovnykh polozhen stvorennia
Derzhavnoi heodezychnoi merezhi Ukrainy" №844 vid 23.12.2009.

7. (1987) Postanovlenie TsK KPSS i Soveta Ministrov SSSR \# 373-85 ot 25 marta 1987.

8. (2007) Stvorennya ta rekonstruktsIya mIstsevih geodezichnih merezh v TsSK-2000. InstruktsIya. K.UkrgeodezkartografIya, 2007. $55 \mathrm{p}$.

9. Teleganov NV, Elagin AV (2004) Vyisshaya geodeziya i osnovyi koordinatno-vremennyih sistem - Novosibirsk: SGGA, 2004. - 238 p.

10. (2000) Topohrafo-heodezychna ta kartohrafichna diyal'nist' (zakonodavchi ta normatyvni akty). - Ch.1. Holovne upravlinnya heodeziyi, kartohrafiyi ta kadastru. K.: Anteks "Vinnytsya", 2000. - 405 p.

11. Hofmann-Wellenhof B, Collins J (1997) Global Positioning Sestem Springer-Vernag, 1997. $389 \mathrm{p}$. 